\title{
GEOGRAFIA DE LUTAS E RESISTÊNCIAS NO TRIÂNGULO MINEIRO: ESTUDOS AGRÁRIOS E DEBATE PARADIGMÁTICO
}

\author{
Janaina Francisca de Souza Campos Vinha \\ Docente do Departamento de Geografia - Universidade Federal do Triângulo Mineiro (UFTM) \\ Docente credenciada no Programa de Pós-graduação em Desenvolvimento Territorial na América Latina e \\ Caribe (TerritoriAL-UNESP) \\ janaina.vinha@uftm.edu.br
}

\begin{abstract}
RESUMO
A história do pensamento geográfico mostra que, desde a sua origem, ela esteve vinculada à interesses específicos e sujeitos e/ou classes sociais hegemômicas. As motivações e os projetos se transformaram, mas ainda sim é necessário desvelar as concepções de mundo desenvolvidas no interior da Geografia. Este trabalho procurou contribuir com a atualização do pensamento geográfico por meio da identificação e análise dos temas e paradigmas da Geografia Agrária mineira. Especialmente neste artigo, as reflexões foram canalizadas na atuação do Triângulo Mineiro na construção de uma Geografia Agrária crítica, denominada de Geografia de Lutas e Resistências. Para tanto, foi proposta uma leitura ancorada no debate paradigmático, abordagem que realça as posturas políticas e ideológicas do conhecimento. No caso da Geografia Agrária, o Paradigma do Capitalismo Agrário (PCA) e - Paradigma da Questão Agrária (PQA) atuaram como aportes dessa reflexão. Foi realizado o levantamento, a sistematização e a análise dos anais e trabalhos do ENGA e SINGA entre 2002 e 2015. Foram organizados 14 anais e 5.239 trabalhos completos, além de elaborada uma planilha com 15 tipos de informações sobre os trabalhos e autores(as). Através da UFU, a região tem contribuído para o avanço dos estudos críticos, os quais compreendem que o desenvolvimento do capitalismo no campo não acontece de forma homogênea, mas é permeado de contradições que possibilitaram historicamente a (re)criação do campesinato. São estudos que se direcionam para o entendimento da luta, do enfrentamento, da resistência e da superação.
\end{abstract}

Palavras-chave: Lutas. Resistências. Debate Paradigmático. Triângulo Mineiro. Geografia Agrária.

\section{GEOGRAPHY OF STRUGGLES AND RESISTANCE IN TRIÂNGULO MINEIRO: AGRARIAN STUDIES AND PARADIGMATIC DEBATE}

\begin{abstract}
The history of geographic thinking shows that, since its origin, it was linked to specific interests and hegemonic subjects and/or social classes. The motivations and projects have been transformed, but it is still necessary to unveil the conceptions of the world developed within Geography. This work sought to contribute to the updating of geographic thinking through the identification and analysis of the themes and paradigms of Minas Gerais Agrarian Geography. Especially in this article, the reflections were channeled in the performance of the Triangulo Mineiro in the construction of a critical Agrarian Geography, called the Geography of Struggles and Resistances. To this end, a reading based on the paradigmatic debate was proposed, an approach that highlights the political and ideological stances of knowledge. In the case of Agrarian Geography, the Agrarian Capitalism Paradigm (PCA) and the Agrarian Question Paradigm (PQA) acted as contributions to this reflection. The survey, systematization and analysis of the annals and works of ENGA and SINGA was carried out between 2002 and 2015. 14 annals and 5,239 completed works were organized, in addition to a spreadsheet with 15 types of information about the works and authors (as). Through UFU, the region has contributed to the advancement of critical studies, which understand that the development of capitalism in the countryside does not happen in a homogeneous way, but is permeated with contradictions that historically made possible the (re) creation of the peasantry. These are studies aimed at understanding the struggle, coping, resistance and overcoming.
\end{abstract}

Keywords: Struggles. Resistances. Paradigmatic debate. Triângulo Mineiro. Agrarian Geography. 


\section{INTRODUÇÃO}

A atividade científica, organizada e constrúida por sujeitos sociais, nunca foi e tampouco será neutra (MORIN, 2008). Apesar de enlouquente no tempo presente, momento em que supostamente as ideologias "tomam conta" das universidades, esse é um debate superado pelas Ciências Humanas e Sociais. Na Geografia, a renovação paradigmática ocorrida no Brasil no início da década de 1980, com o advento da Escola Crítica, desvelou o seu comprometimento ideológico e apontou a utilidade prática e os interesses atrelados à análise espacial, bem como as formas organizativas do Estado e as relações de poder imbuídas (LACOSTE, 1988).

Em meio à instabilidade política posterior ao golpe politico parlamentar-jurídico-midiático de 2016 acometido contra a presidenta Dilma Rousseff e que rompeu a normalidade democrática e constitucional do país, é imprescindível o retorno ao debate sobre a neutralidade das instituições, sobretudo num contexto em que a insana Escola Sem Partido avançou no Brasil. Essa situação acirrou-se em 2019, ano em que as universidades públicas sofreram (e ainda sofrem) inúmeros ataques que colocam em risco sua continuidade e existência enquanto instituição pública, gratuita e de qualidade. Por produzir, na maioria das vezes, conhecimento contestador, questionador e combativo, dissemina-se que o espaço acadêmico seja um "antro" de contaminação ideológica e política, amparada num discurso falacioso que procura legitimar cortes no orçamento público destinado ao Ensino Superior e "calar" a modesta e acanhada massa crítica existente no país.

Pautada na racionalidade, na lógica e no rigor teórico-metodológico, a atividade científica não distancia-se de posicionamentos politicos e ideológicos. Com a Geografia não é diferente. A história do pensamento geográfico mostra que, desde a sua origem, a disciplina esteve vinculada à interesses específicos, sujeitos e/ou classes sociais hegemômicas, estratégica nos projetos de expansão, controle e dominação territorial (LACOSTE, 1988). Aliás, não só a Geografia, mas inúmeras outras disciplinas estiveram à serviço de projetos forjados por grupos dominantes. Tais interesses estão atrelados à ideologias arbitrárias, caracterizadas por serem "[...] racionalistas, 'desejadas' e que merecem ser submetidas a críticas” (GRAMSCI, 1978, p. 62).

$\mathrm{Na}$ contemporaneidade, inúmeros interesses ainda pairam sob a Geografia. É evidente que as motivações e os projetos não são mais os mesmos, mas ainda sim é necessário desvelar quais são as posturas "em jogo". Como parte de uma estrutura amalgada à sociedade, o conhecimento científico também é revestido da concepção de mundo do grupo e/ou indivíduo que a desenvolve. A atividade científica seleciona as questões, os métodos e as teorias que serão estudados (GRAMSCI, 1978), carregadas de sentidos ideológicos e políticos.

É diante desse contexto que o presente trabalho apresenta parte dos resultados obtidos com o desenvolvimento de dois projetos de pesquisa ${ }^{1}$, os quais buscaram contribuir com a história do pensamento geográfico por meio da identificação e análise dos temas e paradigmas da Geografia Agrária brasileira e mineira, revelando suas tendências e perspectivas. Especialmente neste artigo, centramos as reflexões no desvendamento da principal temática de estudo da Geografia Agrária mineira: Luta pela Terra, movimentos sociais e reforma agrária, conjunto denominado neste trabalho por Geografia de Lutas e Resistências. É delineado o papel do Triângulo Mineiro na construção de uma Geografia Agrária crítica, região de Minas Gerais que têm contribuído, nos útlimos anos, para o entendimento das lutas, dos enfrentamentos, das resistências e dos projetos de superação presentes no campo.

Foi proposta uma leitura da Geografia Agrária baseada no debate paradigmático. O debate paradigmático constitui-se num método de análise que dá ênfase às posturas ideológicas e políticas na análise do conhecimento geográfico. No caso da Geografia Agrária, o Paradigma do Capitalismo Agrário (PCA) e o Paradigma da Questão Agrária (PQA) expressam diferentes visões de mundo e figuraram como aportes que conduziram a análise aqui apresentada.

O texto está organizado em três eixos principais: o primeiro faz uma breve incursão sobre as disputas territoriais entre agronegócio/latifúndio e agricultura camponesa em Minas Gerais e no Triângulo Mineiro/Alto Paranaíba. O intuito é apresentar a conflitualidade presente no campo como forma de exaltar as transformações agrárias que compõe o quadro de lutas e resistências e que, por conseguinte, são tomadas como objetos de estudo pela Geografia Agrária. O segundo traz o debate paradigmático, com destaque para o PCA e o PQA. O terceiro eixo aborda os principais temas e

\footnotetext{
${ }^{1}$ Temas e paradigmas da Geografia Agrária brasileira: tendências e perspectivas (CNPq) e Geografia Agrária do Estado de
} Minas Gerais: análise dos temas e paradigmas (FAPEMIG). 
paradigmas da Geografia Agrária mineira, direcionando-se para o que denominamos de Geografia de Lutas e Resistências do Triângulo Mineiro.

\section{DISPUTAS TERRITORIAIS E CONFLITUALIDADE NO TRIÂNGULO MINEIROIALTO PARANAÍBA (MG)}

A hegemonia da agricultura capitalista no campo foi acentuada neste início de século. Sob a égide da política neoliberal, um novo ciclo do capitalismo agrário se redesenha e dá continuidade ao projeto de acumulação e expansão do capitalismo (DELGADO, 2012). Este, ampara-se na territorialização do agronegócio, marcado pelo processo de financeirização da economia, cujo controle é efetivado por grandes corporações transnacionais (FERNANDES; WELCH, 2008). Apesar de ser um modelo que se iniciou no Brasil entre as décadas de 1950 e 1960, converte-se em uma ação orquestrada pelo Estado enquanto economia política do agronegócio nos anos 2000 (DELGADO, 2012). Faz parte de uma construção hegemônica moderna que reestrutura o capital e ultrapassa a dominação clássica ao estilo 'latifúndio improdutivo', de modo que o agronegócio institui-se como elemento que reafirma o processo de modernização da agricultura.

A territorialização da agricultura capitalista agrava a situação da estrutura fundiária brasileira. Segundo o DATALUTA BRASIL (2018), o Brasil apresentou, em 2014, 0,860 no Índice Gini, o que revela uma concentração de terras que varia de forte a muito forte $(0,701$ a 0,900$)$. É evidente que a gênese dos problemas fundiários no Brasil é fruto de um processo da construção histórica da formação da propriedade que inicia-se sob a égide da colonização invasora. Portugal, cuja ordem feudal em 1500 assentava-se no monopólio territorial (neste caso o monopólio da terra), instituiu o modelo latifúndiário existente até hoje no país (GUIMARÃES, 1989).

Tal como o Brasil, a estrutura fundiária de Minas Gerais é concentrada. As mesorregiões que apresentam as maiores desigualdades na distribuição fundiária são Norte de Minas e Noroeste de Minas. O Vale do Jequitinhonha, a região metropolitana de Belo Horizonte, o Vale do Mucuri e a Central mineira também apresentam desigual estrutura fundiária, com concentração que varia de forte a muito forte $(0,701$ a 0,900$)$ em várias das microrregiões (CLEPS JUNIOR; FREITAS; VICTOR, 2014). Nas mesorregiões Norte de Minas, Vale do Jequitinhonha e Vale do Mucuri, o agronegócio se apropria do território através do plantio extensivo de eucaliptos e pinus, empreendidos pela agricultura e pecuária patronal (CLEPS JUNIOR; FREITAS; VICTOR, 2014).

A desigual distribuição fundiária no campo mineiro é fruto das transformações promovidas pelo desenvolvimento do capitalismo que remonta séculos. Com o declínio da mineração no final do século XVIII, a atividade econômica que passou a forjar as condições necessárias para o processo de ocupação do estado foi a agropecuária, que a partir dos anos 1930, desempenhou grande relevância na expansão urbana-industrial de São Paulo. Já nas décadas de 1950 e 1960, Minas Gerais contou com o apoio do Estado, responsável pela implantação de infraestrutura e incentivos que subsidiaram o aquecimento capitalista, sobretudo junto aos processos de modernização de industrialização no campo. Neste momento, houve a "integração" de inúmeras áreas do Cerrado mineiro ao processo produtivo. Tal ocupação, empreendida no período da ditadura militar, visou o desenvolvimento industrial e a expansão da fronteira agrícola direcionado à agricultura patronal.

Essa modernização dolorosa/conservadora possibilitou o avanço e a consolidação do agronegócio na região. A mesorregião geográfica do Triângulo Mineiro/Alto Paranaíba ocupa posição de destaque no cenário agropecuário estadual e nacional. O agronegócio exporta produtos como açúcar, café, milho, soja e seus derivados, sendo significativa a produção e a exportação de produtos nos setores avícola, bovino e suíno.

Entre 2012 e 2015, o agronegócio apresentou um crescimento de mais de $12 \%$ na expansão da sua área no município, enquanto as culturas agrícolas cultivadas pela agricultura camponesa diminuíram cerca de 15\% (MASSON, 2016). A produção de diversas culturas, como abacaxi, alho, arroz, batatadoce, ervilha, tomate não são cultivadas no município. A batata-inglesa, a cebola, o feijão, o girassol e a mandioca (que desapareceu em 2014) são as únicas culturas, além da soja, milho, sorgo e canade-açúcar, presentes na lavoura temporária do município. A produção dessas commodities englobou cerca de $95 \%$ da área plantada e colhida referente a lavoura temporária de Uberaba em 2014. As culturas de cana-de-açúcar, milho, soja, sorgo e café são as únicas que não apresentaram diminuição nas lavouras em Uberaba no período de 2012-2014. A cana-de-açúcar obteve o exorbitante crescimento de 35\% e o sorgo apresentou crescimento de mais de 56\% em 2014 (MASSON, 2016).

$\begin{array}{lllll}\text { Caminhos de Geografia } & \text { Uberlândia-MG } & \text { v. 22, n. } 79 & \text { Fev/2021 } & \text { p. 262-275 Página } 264\end{array}$


A partir dos anos 2000 , período de reestruturação para a economia política do agronegócio, observase na região a massiva e crescente implantação de usinas sucroalcooleiras e a consequente territorialização do capital no campo. Para a safra 2019/20, no Brasil, a área colhida foi estimada em 8,38 milhões de hectares, retração de $2,4 \%$ se comparada com à safra $2018 / 19$. A produção de canade-açúcar, estimada para a safra 2019/20, é de 622,3 milhões de toneladas, acréscimo de $0,3 \%$ em relação à safra anterior. Para Minas Gerais, a projeção é de redução de $1,6 \%$ na área em produção quando comparada à safra anterior. A tendência é de produtividade média $2,7 \%$ maior que à safra 2018/19. Somada às boas condições climáticas, o principal fator para esse incremento é o tecnológico (CONAB, 2019).

No estado de Minas Gerais estão instaladas 42 usinas de etanol e açúcar. Por apresentar topografia, clima e recursos hídricos adequados para o cultivo da cultura, somente no Triângulo Mineiro/Alto Paranaíba há 25 unidades, ou seja, a região concentra mais da metade das usinas do estado, distribuídas em mais de 20 municípios (NOVA CANA, 2019).

A territorialização do setor sucroalcooleiro na região é estratégica. O agronegócio situa-se no chamado Polígono do Agrohidronegócio, área que a mesorregião se localiza, usurpando água de centenas de milhares de trabalhadores e abastecendo sistemas de irrigação de outras lavouras comerciais, como a soja e o milho. O processo de expansão do agronegócio se consolida territorialmente em várias porções do espaço, conciliando os interesses em controlar as melhores terras e o acesso à água (CLEPS JUNIOR; CARVALHO; FREITAS, 2012). Assim, além da territorialização, o agronegócio também interfere no controle hídrico.

Como visto, a volupiosa presença e pujança do agronegócio e do latifúndio na região dá indícios do modelo de desenvolvimento adotado para o campo no país e no estado. Entretanto, partimos do pressuposto que o desenvolvimento do capitalismo no campo ocorre de forma desigual e contraditória (OLIVEIRA, 1999), pois mesmo diante da intensa territorialização do agronegócio em Minas Gerais, especialmente na região do Triângulo Mineiro/Alto Paranaíba, combina-se outro movimento: a (re)produção do campesinato. A luta pela terra e a política de reforma agrária revelam esse processo, assumindo que um dos estados mais ricos e industrializados da federação ainda não resolveu as questões voltadas à distribuição de terras. $\mathrm{O}$ crescimento extraordinário da economia agrícola mineira não foi compartilhado pelos trabalhadores que produziram essa riqueza, e o aumento da produção e renda ficou concentrado nas mãos daqueles que detêm os meios de produção. No caso da agricultura, naqueles que controlam o poder da propriedade privada, muitas vezes objeto de expropriações, violências e grilagens.

Em seu desenvolvimento desigual, o modo capitalista de produção gera inevitavelmente a expropriação e a exploração. Os expropriados ocupam a terra como forma de reproduzir o trabalho familiar. Assim, a luta pela terra é uma luta constante contra o capital, a expropriação e a exploração (FERNANDES, 2001). Na região do Triângulo Mineiro/Alto Paranaíba as lutas espacializam e territorializam o campesinato via movimentos socioterritoriais, considerada a mesorregião com o maior número de conflitos do estado - 258 ocupações entre 1990-2016 e 88 assentamentos criados no período de 1986-2016 (DATALUTA MINAS GERAIS, 2017). As ocupações e manifestações são formas de especializar e territorializar a luta camponesa. São ações de resistência desenvolvidas na trajetória da luta, diferenciadas em todo o Brasil (FERNANDES, 2001).

Ocupar os latifúndios, durante muito tempo, foi a principal ação da luta pela terra dos movimentos socioterritoriais. Elas contestam, diretamente, a propriedade privada, estratégia que possibilitou a parca e frágil política de reforma agrária no país. Quase $80 \%$ dos assentamentos implantados nas regiões Sul e Sudeste, nos estados de Mato Grosso do Sul e Goiás, e nos estados do Ceará, Alagoas, Sergipe e Pernambuco, são fruto das ocupações de terra (FERNANDES, 2001).

$\mathrm{Na}$ atualidade, além das ocupações de terra, os movimentos têm se articulado junto às manifestações no campo. Elas também são consideradas estratégias de luta e resistência organizadas pelos movimentos socioterritoriais que reivindicam condições dignas e justas para o campesinato. A maioria das manifestações ocorrem nas cidades e em grandes centros urbanos, e visa denunciar, ao tornar público, as mazelas e os problemas sociais. Configura-se como maneira de pressionar o Estado e, ao mesmo tempo, despertar a consciência crítica na população das cidades (PEREIRA, 2012).

Para se ter uma ideia do significado dessas ações, no Brasil, entre 2000-2017, foram 12.554 manifestações com 7.049.073 famílias envolvidas. Só no ano de 2017, foram mais de 396 mil famílias. Em Minas Gerais, em 2016, foram 821 manifestações e mais de 460 mil famílias, o maior 
número dentre as unidades federativas da região Sudeste (DATATUTA MINAS GERAIS, 2017). No Triângulo Mineiro/Alto Paranaíba, foram registradas 96 manifestações do campo entre 2000-2016 (DATALUTA MINAS GERAIS, 2017).

Em Minas Gerais, Belo Horizonte é o município com a maior incidência de manifestações, seguida por Uberlândia. A região do Norte e o Triângulo Mineiro, juntamente com BH, representam mais de $70 \%$ das ações recorrentes no estado e $65 \%$ das pessoas envolvidas. Especificamente na região do Triângulo Mineiro/Alto Paranaíba, os tipos mais comuns de ações são acampamentos, audiências, bloqueios de rodovia, caminhadas, concentração em espaços públicos, manifestos, marchas, ocupações de prédios público e privado, pedidos de demissão, romarias e vigílias, sendo bloqueio de rodovias a manifestação mais expressiva, seguida pela concentração em espaços públicos (VICTOR, 2016). Uma das principais questões desta região que mobilizam as famílias camponesas nas manifestações é a questão da terra, a qual expõe a necessidade da realização da política de reforma agrária, a desapropriação de terras, os incentivos à pequena produção, entre outros (VICTOR, 2016).

Enquanto as ocupações traduzem-se como ferramentas de acesso à terra que potencializam a criação de assentamentos rurais, contestando diretamente a exclusão e a expropriação no campo, as manifestações representam a continuidade de um processo de lutas e (re)produção do campesinato. Esse processo se inicia com a conquista do assentamento, uma vez que a luta pela permanência na terra é uma realidade que prossegue afligindo e mobilizando ações nas cidades.

É diante dessa realidade contraditória de lutas e resistências contra o capital é que os estudos agrários no Triângulo Mineiro necessitam ser compreendidos. A aproximação do sujeito ao objeto, isto é, do pesquisador ao espaço agrário, se constitui uma via de mão dupla entre conhecimento e realidade. Ao passo que o campo se transforma, leituras sobre essa realidade se inscrevem e compõe o conhecimento; o conhecimento, por sua vez, possibilita que a realidade seja continuamente interpretada. Isso mostra como as recentes transformações na sociedade brasileira influenciam as mudanças dos temas de pesquisa, mantendo alguns, criando novos e fazendo desaparecer outros (FERREIRA; 1998; 2002).

Ao estudar a realidade do espaço agrário mineiro, as pesquisas também revelaram diferentes visões de mundo, as quais podem estar explícitas e/ou implícitas. É neste momento que o debate paradigmático comparece como abordagem que alicerça esse trabalho, pois além de revelar os temas de pesquisa, dá ênfase às posturas ideológicas e políticas na análise do conhecimento, ou seja, aos paradigmas. No caso da Geografia Agrária, o PCA e o PQA manifestam essas posturas e as diferentes visões de mundo. Com isso, propõe dar continuidade aos estudos sobre o pensamento geográfico, atualizando-o e concebendo-o diante de "novas" dimensões que permeiam a construção do conhecimento. No caso do Triângulo Mineiro, como será debatido, as temáticas estudadas manifestam o sentido das lutas e resistências no campo, com a superação e enfrentamento ao capitalismo - PQA.

\section{DEBATE PARADIGMATICO COMO ABORDAGEM PARA A LEITURA DA GEOGRAFIA AGRÁRIA}

O debate paradigmático é um método de análise que vem sendo trabalhado por estudiosos como Fernandes (2005; 2006; 2008; 2009; 2013), Carvalho (2005), Girardi (2008), Ramos Filho (2008), Campos; Fernandes (2011), Felício (2011), Campos (2012) e Camacho (2014). O debate paradigmático é uma opção interpretativa de análise do conhecimento produzido pela Geografia Agrária que, além de identificar temas e paradigmas, também evidencia a postura política-ideológica contida nas pesquisas sobre o desenvolvimento do campo. Evidente que as pesquisas sobre o campo brasileiro não se resumem à análise paradigmática, mas adotá-la é uma questão de método (MORIN, 2008), considerada imprescindível nesse trabalho (FELÍCIO, 2011).

O debate paradigmático como abordagem para a leitura da Geografia Agrária teve início em Campos (2012). O trabalho analisou os temas e paradigmas da Geografia Agrária, elucidando que os grupos de pesquisa do estado de São Paulo são espaços de socialização do conhecimento que compartilham temas e paradigmas. O cerne da discussão centrou-se na produção do conhecimento científico (paradigmas) e na sua relação com distintas posições político-ideológicas, resultando em disputas acadêmicas que debatem diferentes modelos de desenvolvimento para o campo. Dentro dessa interpretação, a universidade e os grupos de pesquisa são territórios políticos que, ao socializar o conhecimento produzido, participam de uma disputa teórico-metodológica e políticoideológica denominada debate paradigmático.

Em Campos (2012), também discutiu-se o método como uma construção intelectual que permite

$\begin{array}{lllll}\text { Caminhos de Geografia } & \text { Uberlândia-MG } & \text { v. 22, n. } 79 & \text { Fev/2021 } & \text { p. 262-275 Página } 266\end{array}$


abordar uma realidade, a partir de um ponto de uma visão de mundo (MORIN, 2008). Sua lógica é construída pela liberdade e autonomia de escolha dos referenciais teóricos, o qual pode ser constituído pelo seu próprio pensamento ou pela subordinação a outros pesquisadores (FERNANDES, 2009). Com o auxílio do método, podemos ler a realidade por várias "portas de entrada": podemos interpretar, dialeticamente, o que produziram autores neopositivistas ou fenomenólogos e vice-versa [...]" (SPOSITO, 2004, p. 50).

É por isso que o debate paradigmático é concebido como um método de análise, pois a partir de uma construção intelectual é possível compreender a realidade, neste caso, a Geografia Agrária, numa aproximação entre diferentes paradigmas, leituras científicas, políticas e ideológicas (FERNANDES, 2013). Refletir como os estudiosos entendem o campesinato, a luta pela terra, a pluriatividade ou mesmo os movimentos sociais, é um excelente exemplo. Cada qual irá compreender uma mesma temática de acordo com seus paradigmas, ou até mesmo selecionar uma delas de acordo com suas posturas políticas e ideológicas.

Segundo Fernandes (2013), a intencionalidade é um aspecto importante do debate paradigmático. Em cada pesquisa há a intenção (explícita ou implícta) de defender paradigmas. Mesmo de forma implícita, os pesquisadores "transitam por esses territórios epistemológicos, onde a filosofia e a ciência se encontram (Japiassu, 1979)" (FERNANDES, 2013, p. 65). Mais do que ciência, como já exaltado, política e ideologia entrecruzam a atividade científica. O processo de construção do conhecimento é permeado pela práxis intelectual e política organizada pelos pesquisadores, e "[...] nenhum trabalhador intelectual está fora deste processo, nem os que trabalham em grupos de pesquisas, em redes nacionais e internacionais, e nem mesmo aquele que trabalha sozinho" (FERNANDES, 2013, p. 66).

No que diz respeito à Geografia Agrária, o debate científico, é, ao mesmo tempo, um debate políticoideológico que sintetiza, sobretudo, dois paradigmas que enxergam o desenvolvimento do campo de formas distintas: PCA e o PQA.

O PCA compreende que o modelo de desenvolvimento do campo depende da integração ao sistema capitalista e deve correr paralelamente às estruturas de mercado e controle do Estado. As desigualdades ocasionadas pelo sistema são conjunturais e devem ser superadas por meio de políticas públicas que possibilitem a "integração" do "agricultor familiar" ao mercado capitalista. O PCA possui duas tendências: da agricultura familiar, que acredita na integração das famílias ao capital, e do agronegócio, que não acredita na agricultura familiar, entendendo-o como categoria deve ser eliminada para que o campo alcance patamares maiores de desenvolvimento econômico e social.

A gênese do PCA está nas obras de Henri Mendras e Hugues Lamarche (FELÍCIO, 2011). Este paradigma alcançou ímpeto na década de 1990 com a tese de doutorado do economista Ricardo Abramovay, publicado no formato de livro no ano de 1992, intitulado "Paradigmas do Capitalismo Agrário em Questão". Nesta obra, o autor opôs-se à visão marxista e defendeu que os países ricos capitalistas, ao invés da proletarização, estariam integrados ao mercado, já que nesses a agricultura familiar apresentou uma participação expressiva. O problema não reside no capitalismo que expropria os sujeitos de seus territórios, mas no campesinato que, por ser caracterizado como uma sociedade parcial e de mercado incompleto, não se adéqua ao sistema capitalista. "[...] Abramovay inverte o sentido dado pelo paradigma da Questão Agrária: o problema não está no capitalismo, mas sim no campesinato" (FERNANDES, 2005, p. 15).

O método do PCA alicerça-se nos processos determinantes e dominantes do capital, transformando (metamorfoseando) o sujeito camponês para adequá-lo e inseri-lo no mercado, isto é, transformá-lo em agricultor familiar. As relações que fazem parte do processo de desenvolvimento do capitalismo na agricultura possibilitam compreensões distintas e, por isso, permitem que o camponês seja metamorfoseado e o coloca dentro de paradigmas divergentes (FERNANDES, 2005).

No PQA, não se nega a participação no mercado, mas defende-se que ela se faça concomitante a promoção da luta pela terra e pela reforma agrária. A perspectiva está na transformação da sociedade, no enfrentamento e na superação do capitalismo, sendo a luta pela terra uma luta contra o capital. Esse paradigma possui duas tendências: da proletarização, que enfatiza a relação entre capital e trabalho, e do campesinato, que preconiza as relações sociais camponesas e os processos de luta e enfrentamento ao capital.

Sua gênese está em pensadores como Karl Marx, Karl Kautsky, Vladimir Lênin, Alexander Chayanov, Rosa Luxemburg e Teodor Shanin (FELÍCIO, 2011). Eles são referenciais seminais para o estudo da questão agrária por versarem sobre os desdobramentos do avanço do capitalismo no campo. Kautsky 
e Lenin, principais pensadores desse paradigma, apostaram no fim do campesinato, assentados no pressuposto de sua eliminação em decorrência do avanço do capitalismo no campo, no entanto, para ambos, havia a perspectiva de superação do campesinato dentro do sistema socialista. Suas perspectivas exaltaram os camponeses como sujeitos ativos na luta contra o capital e na superação do sistema capitalista. Kautsky e Lenin admitiram a conflitualidade, em que o enfrentamento, a luta de classes e a resistência deveriam ser consideradas.

A conflitualidade é um conceito importante para o PQA na análise dos modelos de desenvolvimento da agricultura. O movimento de destruição e recriação de relações sociais demonstra a conflitualidade entre diferentes modelos (FERNANDES, 2005). Por aceitar a conflitualidade, o escopo de análise deste paradigma não se limita à lógica do capital. $O$ enfretamento à este modo de produção é condição para a recriação do campesinato. Pesquisas que trazem a perspectiva da luta pela terra, como movimentos sociais/socioterritoriais, assentamentos rurais, ocupações de terras, disputas territoriais, políticas públicas e manifestações, por exemplo, revelam o enfrentamento à lógica imposta. São pesquisas que não se limitam à reprodução econômica e enveredam para a reprodução da existência do campesinato enquanto sujeito político, capaz de promover mudanças e transformações.

Em síntese, para o PQA, o problema está no capitalismo, e para o PCA, o problema reside no campesinato. Essas duas visões de mundo representam a conflitualidade que o conhecimento científico está mergulhado (CAMPOS, 2012). Embora distintos, pressupõe-se que não são paradigmas excludentes, já que a existência de um não elimina a existência do outro, mas demonstram a pluralidade paradigmática, marcada pela unidade, diversidade e diferencialidade da produção geográfica. Esses paradigmas possuem posturas políticas e ideológicas que os diferenciam no entendimento sobre o avanço do capitalismo no campo.

A diferencialidade destas posturas paradigmáticas está na direcionalidade que as visões de mundo propõem. Para os que perfilham o PQA, além do reconhecimento dos limites do capitalismo, existe uma postura teórica e político-ideológica bem demarcada de superação, fazendo desse problema a centralidade das suas pesquisas. Já quando o limiar das pesquisas não sinaliza indícios do processo de luta e superação, mas apenas aponta as desigualdades fomentadas pela lógica capitalista, o PCA coloca-se como horizonte e perspectiva de análise.

Ao propor o debate paradigmático, a questão não é demonstrar uma suposta superioridade científica de qualquer um deles, tampouco reduzir ou dicotomizar em dois paradigmas toda a riqueza da Geografia Agrária. Busca-se confrontar as perspectivas e evidenciar o tom político e ideológico presente no pensamento geográfico e que resulta na unidade, diversidade e diferencialidade temática e paradigmática da Geografia Agrária (CAMPOS, 2012).

Refletir o pensamento geográfico diante dessa abordagem representa, apenas, uma proposta de leitura da realidade dentre as inúmeras que possam existir. Ela é parcial como todos os trabalhos acadêmicos porque, mesmo no maior dos seus esforços, nunca conseguirá captar a totalidade e será imparcial.

\section{GEOGRAFIA DE LUTAS E RESISTÊNCIAS: TRIÂNGULO MINEIRO EM FOCO}

Para identificar e analisar os principais temas e paradigmas da Geografia Agrária mineira, optou-se por pesquisar os dois mais importantes eventos científicos da Geografia Agrária: o Encontro Nacional de Geografia Agrária (ENGA) e o Simpósio Internacional de Geografia Agrária (SINGA). São nos eventos científicos, espaços interativos e coletivos, que os geógrafos(as) defendem diferentes propostas, portanto, é onde o debate paradigmático pode ser apreendido.

Foi realizado um exaustivo levantamento, sistematização e análise dos anais e trabalhos do ENGA e SINGA no período de 2002-2015. Foram organizados 14 anais, registrados 5.239 trabalhos completos, além de elaborada uma planilha com 15 tipos de informações sobre os trabalhos e autores(as).

Antes de refeltir sobre o papel do Triângulo Mineiro na construção de uma Geografia Agrária crítica é importante caracterizar o conjunto de pesquisas e pesquisadores que foram incorporados na análise delineada nesse artigo.

Desses 5.239 trabalhos, Minas Gerais é reponsável por 632 trabalhos, isto é, $12 \%$ do total. Um dos fatores que explica esse elevado número associa-se à consolidação científica que a região Sudeste historicamente apresentou. No que diz respeito à participação das instituições, mais de $95 \%$ são

$\begin{array}{lllll}\text { Caminhos de Geografia } & \text { Uberlândia-MG } & \text { v. 22, n. } 79 & \text { Fev/2021 } & \text { p. 262-275 Página } 268\end{array}$


públicas. Este dado aponta para protagonismo das universidades públicas, centros de excelência na produção do conhecimento geográfico. As universidades públicas estão baseadas no tripé ensino, pesquisa e extensão, condição que conduz a mudanças significativas nos processos de ensino e aprendizagem, e pode colaborar de forma efetiva para a formação acadêmica. Além de universidades, participaram a Escola Família Agrícola, os Centros e Institutos federais.

A universidade que mais comparece é a Universidade Federal de Uberlândia (UFU), com 336 trabalhos, sinalizando para o seu importante papel na construção científica da Geografia Agrária no estado - que é quase seis vezes superior a universidade da capital mineira, a Universidade Federal de Minas Gerais (UFMG), que ocupa o 20 lugar na publicação de trabalhos. Ainda comparece em destaque a Universidade Federal de Montes Claros (55), a Universidade Federal de Alfenas (47), a Universidade Federal de Juíz de Fora (45), a Universidade Federal de Viçosa (35) e a Universidade Federal de São João del-Rei (17) (Quadro 1).

Quadro 1 - Minas Gerais - Principais universidades com publicações em Geografia Agrária (2002-2015).

\begin{tabular}{|c|c|c|}
\hline \multicolumn{2}{|c|}{ UNIVERSIDADE } & $N^{\circ}$ TOTAL DE PUBLICAÇÕES \\
\hline 1 & UFU & 336 \\
\hline 2 & UFMG & 55 \\
\hline 3 & UNIMONTES & 47 \\
\hline 4 & UNIFAL & 45 \\
\hline 5 & UFJF & 35 \\
\hline 6 & UFV & 17 \\
\hline 7 & UFJS & 2019. \\
\hline
\end{tabular}

Juntas, essas universidades concentram 535 trabalhos, cerca de $85 \%$ do total de MG. Sem dúvida, essa expressão coloca em evidência o protuberante papel da universidade pública na produção e difusão da ciência brasileira - neste caso, dos estudos agrários geográficos. Em 2016, a PEC-55, assinada pelo ex-presidente Michel Temer, congelou os gastos públicos na educação por 20 anos. Junto ao contingenciamento de recursos federais às universidades de 2019, certamente, esses dois episódios trarão grandes rebatimentos ao desenvolvimento do trabalho científico no Brasil, implicando sensivelmente na produção científica nacional.

É notória a centralidade e presença do Triângulo Mineiro, através da atuação da UFU nos encontros especialmente o Laboratório de Geografia Agrária (LAGEA). Outro grupo responsável por grande parte da produção de trabalhos é o Laboratório de Geografia Agrária, Agricultura Familiar e Cultura Camponesa, ligado institucionalmente ao Departamento de Geografia do Instituto de Geociências (IGC) da UFMG, que atualmente abarca o Núcleo Terra \& Sociedade de Estudos em Geografia Agrária, Agricultura Familiar e Cultura Camponesa, registrado no CNPq. A UNIFAL também vem avançando consideravelmente no debate agrário. O grupo com maior representatividade na produção de trabalhos é o Grupo de Estudos Regionais e Socioespaciais (GERES).

Como apontado, a UFU foi responsável pela maior parcela de trabalhos. Dos 632 trabalhos de instituições de MG, cerca de 337 foram produzidas pela instituição, representando mais da metade do total. Quando analisados apenas os anais do ENGA, das 244 produções mineiras, 151 foram originadas na UFU - cerca de $61 \%$.

O LAGEA foi criado em 1997 junto ao Departamento de Geografia da UFU com a finalidade de desenvolver projetos de pesquisa, ensino e extensão atinentes ao espaço agrário. O LAGEA agrega o Núcleo de Estudos Agrários e Territoriais (NEAT), vinculado ao CNPq e ao laboratório desde 1997. No grupo, há treze linhas de pesquisas cadastradas: "Agricultura Camponesa e Produção Familiar", "Comunidades Rurais e Populações Tradicionais", "Desenvolvimento e Economia Solidária", "Desenvolvimento Regional e Transformações Socioespaciais”, "Educação do Campo", "Educação do Campo e Juventude Rural", "Gestão do Espaço Rural e Meio Ambiente", "Modernização Agrícola e Agronegócio", "Políticas Públicas e Agricultura Sustentável", "População, Território e Políticas Públicas", "Questões Teórico-metodológicas da Geografia Agrária", "Reforma Agrária e

$\begin{array}{lllll}\text { Caminhos de Geografia } \quad \text { Uberlândia-MG } & \text { v. 22, n. } 79 & \text { Fev/2021 } & \text { p. 262-275 Página } 269\end{array}$


Assentamentos Rurais" e "Território, Identidade e Territorialidades".

A UFU se tornou um dos polos mais importantes para a discussão da Geografia Agrária no Brasil, fato que projeta o Triângulo Mineiro no que intitulamos de Geografia de Lutas e Resistências ${ }^{2}$, reunindo 55 trabalhos que versam sobre a luta pela terra, movimentos sociais e reforma agrária (Tabela 1). Se retomadas as temáticas apontadas por Ferreira (1998) na década de 1990, para o início do século XXI, Luta pela terra, movimentos sociais e reforma agrária permanece em destaque como um dos temas mais estudados pela Geografia Agrária mineira, com 78 trabalhos no total (VINHA, 2019). Este tema representa mais de $12 \%$ do total dos trabalhos no estado, e indica que os estudos críticos, pautados no PQA, com a concepção do enfrentamento e superação ao capitalismo, mantêm a notoriedade neste início de século (VINHA, 2019).

Tabela 1 - Principais temas da Geografia Agrária - UFU (2002-2015).

\begin{tabular}{|c|c|}
\hline Temáticas & N. de trabalhos \\
\hline Modernização do campo, agronegócio e latifúndio & 62 \\
\hline Luta pela terra, movimentos sociais e reforma agrária & 55 \\
\hline Diâmicas da natureza e questão ambiental & 25 \\
\hline Campo/cidade e rural/urbano & 23 \\
\hline Educação e educação do/no campo & 23 \\
\hline Agricultura familiar e agricultura camponesa & 20 \\
\hline Estado, políticas públicas e desenvolvimento & 18 \\
\hline Disputas e conflitos & 13 \\
\hline Mudanças e dinâmicas socioespaciais & 12 \\
\hline Êxodo rural e migração & 11 \\
\hline Abordagens teórico-metodológicas & 10 \\
\hline Geocartografia, geoprocessamento e geotecnologias & 10 \\
\hline Comunidades tradicionais & 9 \\
\hline Agroeneria, barragens e mineração & 8 \\
\hline Relações de trabalho & 7 \\
\hline Renda, mercados e comercialização & 7 \\
\hline Agricultura orgânica e agricultura agroecológica & 6 \\
\hline Produção agropecuária & 6 \\
\hline Comunidades indígenas & 3 \\
\hline Cooperativismo e associativismo & 3 \\
\hline Gênero & 2 \\
\hline Pluriatividade & 1 \\
\hline Soberania alimentar e segurança alimentar & 1 \\
\hline Uso e ocupação do solo & 1 \\
\hline Outras & 1 \\
\hline TOTAL & 337 \\
\hline
\end{tabular}

Fonte - Anais do ENGA e SINGA (2002-2015). Organização: Janaina Francisca de Souza Campos Vinha (2019).

${ }^{2}$ O título foi inspirado no livro Geografia das Lutas no Campo, de Ariovaldo Umbelino de Oliveira (1988).

$\begin{array}{lllll}\text { Caminhos de Geografia } \quad \text { Uberlândia-MG } & \text { v. 22, n. } 79 & \text { Fev/2021 } & \text { p. 262-275 Página } 270\end{array}$


Os trabalhos referem-se, sobretudo, ao processo de luta pela terra como um processo de resistência e (re)criação do campesinato brasileiro; a atuação dos movimentos sociais/socioterritoriais, com enfoque para as estratégias de espacialização, territorialização e desterritorialização; geração de renda; cooperativismo; desenvolvimento territorial; organização, dinâmica e transformações territoriais nos assentametos; destaque para o conceito de território; ocupações de terra; violência no campo; os assentamentos e os acampamentos como espaços de luta e resistência; política de reforma agrária; juridiciação e criminalização da luta e dos movimentos; conflitos com o agronegócio e o lalifúndio, a produção para o mercado e subsistência nos assentamentos e a reforma agrária de mercado como política de terra do Banco Mundial; os modos de vida, identidade e cultura; sustentabilidade; acesso a crédito, assistência técnica e políticas públicas; territorialidades e territorialização; produção agropecuária e formação e mobilização política.

Com 79 trabalhos, Modernização do campo/agronegócio e latifúndio é outra temática mais estudada em Minas Gerais, e no caso da UFU, foram identificados 62 trabalhos. Importante observar que essa, juntamente da temática anterior, são, também, as duas principais da Geografia Agrária brasileira, demonstrando que o estado vem acompanhando as discussões que permeiam o território nacional (VINHA, 2019). Para o Triângulo Mineiro, como já explicitado na primeira secção, o protagonismo desses dois grandes temas explica-se pela conflitualidade intrínseca do agronegócio na região, desdobrando-se em disputas territoriais entre a agricultura camponesa e a a agricultura capitalista - latifúndio e agronegócio.

Foram denunciados os mitos sobre o desenvolvimento do agronegócio; os impactos ambientais; os riscos contra a biodiversidade; a expansão e territorialização do capital e das commodities; o agronegócio como fator determinante para a criação e expansão das cidades e, por conseguinte, para a reorganização espacial; reestruturação produtiva; a transgenia; a análise da territorialização e territorialidade agroindustrial; as redefinições técnico-produtivas do capital; o sistema de logística e transportes; as mudanças na estrutura fundiária; agroexportação; Mercado de terras; expansão da fronteira agrícola. O segmento sucroalcooleiro, sojeiro, agropecuário e avícola foram os mais apontados, enfatizando, igualmente, as novas formas de territorialização, como o agrohidronegócio, a monocultura da cana e a estrangeirização da terra. Além do agronegócio, porém em menor proporção, também foram identificadas pesquisas sobre a persistência do latifúndio e da grilagem, considerada base fundante para o desenvolvimento do agronegócio.

Não foram registrados trabalhos que apontaram o agronegócio como modelo de desenvolvimento para o campo. A nuance crítica foi majoritária. Diferente da temática Luta pela terra, movimentos sociais e reforma agrária, os trabalhos categorizados em Modernização do campo, agronegócio e latifúndio não argumentaram cientificamente sobre os benefícios sociais e/ou econômicos da agricultura capitalista, mas revelaram suas contradições e entraves ao desenvolvimento regional e territorial e o avanço da territorialização do agronegócio.

Embora sejam caracterizados como críticos, nem todos esses trabalhos compartilharam do PQA. Em Campos (2012), ao analisar o conhecimento geográfico no Estado de São Paulo, por exemplo, haviam pesquisadores que mesmo exaltando as contradições e mazelas engendradas pelo avanço do capitalismo no campo, revelando suas problemáticas junto à comunidades camponesas, tradicionais e/ou indígenas, a perspectiva da superação ao sistema não compareceu. Está é uma questão tênue sobre o PQA e PCA: "[...] para alguns pesquisadores, a crítica limita-se à crítica, ou seja, por mais que sejam admitidos os problemas do sistema capitalista, não há um tom de enfrentamento, transformação e superação dessa lógica. Os problemas são expostos, porém, não são colocados no cerne das discussões que envolvem suas pesquisas" (CAMPOS, 2012, p. 219).

Além dos principais temas da Geografia mineira, também foi possível identificar a evolução das temáticas em cada edição do evento (Gráfico 1). 
Gráfico 1 - Minas Gerais - Evolução dos principais temas da Geografia Agrária (2002-2015).

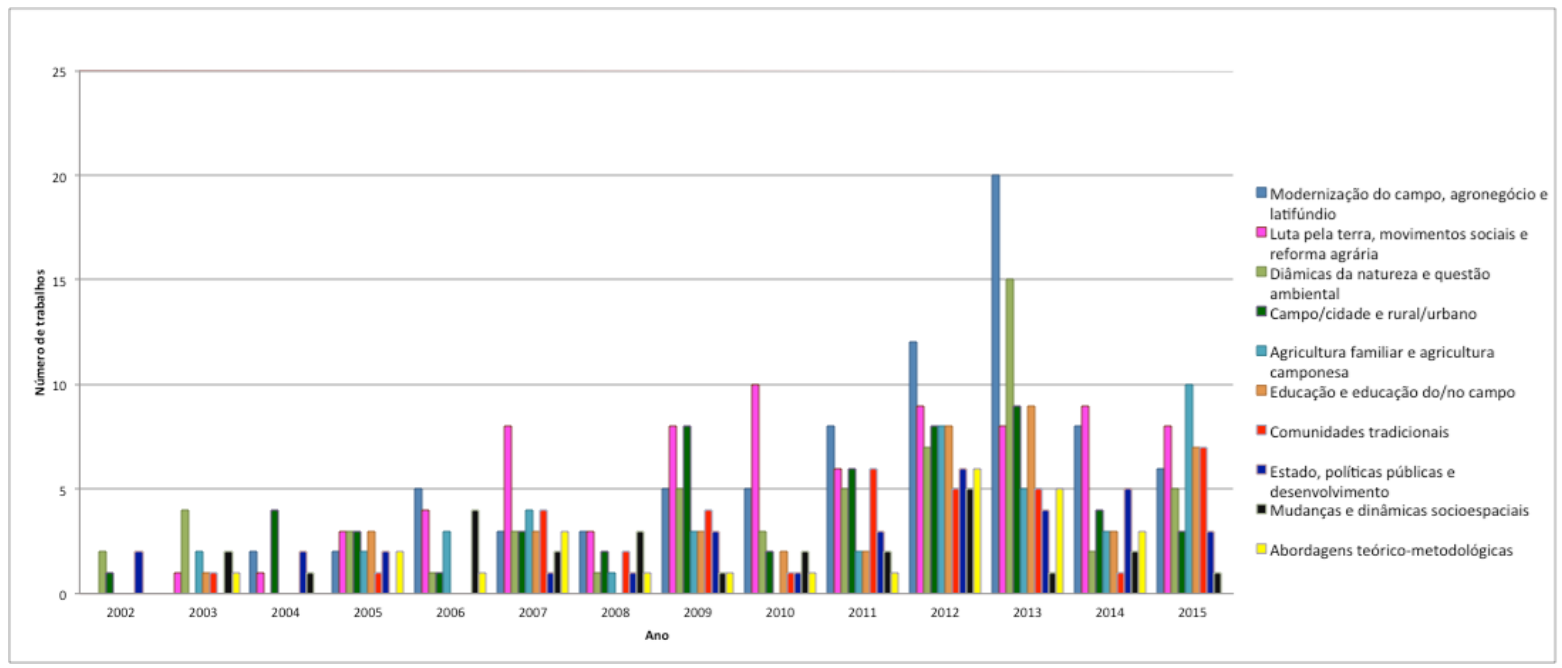

Fonte - Anais do ENGA e SINGA (2002-2015). Organização: Janaina Francisca de Souza Campos Vinha (2019).

Além do crescimento da participação mineira, é inegável o aumento da diversidade de temas da Geografia Agrária, o que expressa a complexidade no estudo do campo brasileiro e as posturas políticas e ideológicas: Dinâmicas da natureza e questão ambiental (56), Campo/cidade e Rural/urbano (54), Agricultura familiar e agricultura camponesa (43), Educação e educação do/no campo (41), Comunidades tradicionais (37), Estado, políticas públicas e desenvolvimento (33), Mudanças e dinâmicas socioespaciais (26) e Abordagens teórico-metodológicas (25). Esses temas convergem para as linhas de pesquisa do NEAT/UFU, e revelam as contribuições desse coletivo de pensamento junto aos estudos agrários.

O gráfico destaca o crescimento da temática Modernização do campo, agronegócio e latifúndio, que no ano de 2013 apresentou um aumento significativo. Essa dinâmica pode ser entendida a partir da expansão do setor sucroalcooleiro no estado, que passou a ser um dos maiores produtores de cana do país. Dinâmicas da natureza e questão ambiental também cresceu consideravelmente no período analisado. Tais estudos caminharam para duas direções: escancaram os efeitos nefastos do desenvolvimento da agricultura capitalista sob a natureza e afloraram as relações entre povos tradicionais e camponeses, cuja territorialidade e cultura expressam um vínculo entre modo de vida e modo de produção específico desses sujeitos.

É importante destacar o horizonte de temas que se abrem na Geografia e que pouco a pouco vão ganhando tônica. O estudo sobre as comunidades tradicionais e a educação do campo, por exemplo, cresceram no período analisado, e corroboram para a continuidade de uma Geonrafia comprometida com interesses e projetos emancipatórios que dialoguem com as demandas da classe trabalhadora.

A discussão sobre os processos de luta é uma das temáticas que permanece em destaque, e indica que os estudos críticos, pautados no PQA, ganharam notoriedade neste início de século. Isso demonstra a necessidade de analisar o campo brasileiro a partir das contradições do desenvolvimento do capitalismo no campo, o qual impõe condições sublaternas e exploratórias à agricultura camponesa. A temática alinha-se às lutas presentes no campo, à resistência e ao protagonismo dos movimentos socioterritoriais nas suas reivindicações. Ilustra a construção de uma Geografia Agrária crítica, ancorada numa análise espacial que reconhece as desigualdades, injustiças, disputas e conflitos que travejam o espaço agrário brasileiro. 


\section{CONSIDERAÇÕES FINAIS}

O Triângulo Mineiro/Alto Paranaíba é considerado uma das regiões mais conflituosas do estado. As disputas territoriais são acirradas no embate entre a territorialização do agronegócio e o movimento de lutas do campesinato, evidenciando a conflitualidade inerente do capitalismo. Na procura por investigar essa realidade, a Geografia vem tentando construir análises, lançando mão de artefatos científicos que manifestam diferentes visões de mundo sobre o espaço geográfico. Tais visões, fundadas em posturas ideológicas e políticas, são compreendidas como paradigmas, e na Geografia Agrária tem o potencial de exaltar distintas perspectivas sobre o campo - PCA e PQA.

Ao fazer uma reflexão sobre os temas e paradigmas da Geografia Agrária, essa conflitualidade compareceu com grande peso na produção geográfica crítica das universidades mineiras. Categorizadas em distintas temáticas, o principal eixo de estudo foi denominado Geografia das Lutas e Resistências, o qual deu centralidade às análises sobre os processos de luta pela terra, política de reforma agrária e movimentos sociais, desnudando um espaço agrário permeado de conflitos e tensões. A UFU é a principal instituição do estado, responsável por mais da metade de trabalhos. A complexa e latente questão agrária brasileira é renovada constantemente e incorporada à Geografia, revelando-se como disciplina que se distancia de uma suposta neutralidade científica ao focalizar o PQA, com estudos que explicitam o enfrentamento, a resistência e a superação das desigualdades presente no campo. Revelou-se uma Geografia Agrária diversa, ampla e plural e que, em sua essência, está comprometida com as questões sociais que historicamente marcaram o campo.

\section{REFERÊNCIAS}

CAMACHO, Rodrigo Simão. Paradigmas em disputa na Educação do campo. 2014. $806 f$. (Doutorado em Geografia) - Faculdade de Ciências e Tecnologia (FCT), Universidade Estadual Paulista (UNESP), Campus de Presidente Prudente, Presidente Prudente.

CAMPOS, Janaina Francisca de Souza; FERNANDES, Bernardo Mançano. O conceito de paradigma na geografia: limites, possibilidades e contribuições para a interpretação da Geografia Agrária. Campo-território: Revista de geografia agrária, v. 6, n. 11, p. 21-52, fev., 2011.

CAMPOS, Janaina Francisca de Souza. Leituras dos territórios paradigmáticos da Geografia Agrária: análise dos grupos de pesquisa do estado de São Paulo. 2012. 389f. (Doutorado em Geografia) - Faculdade de Ciências e Tecnologia (FCT), Universidade Estadual Paulista (UNESP), Campus de Presidente Prudente, Presidente Prudente.

CARVALHO, Horácio Martins de. $\mathbf{O}$ campesinato no século XXI: possibilidades e condicionantes do desenvolvimento do campesinato no Brasil. Petrópolis: Vozes, 2005.

CLEPS JUNIOR, João; CARVALHO, L.; FREITAS, Ricardo, Luis de. A territorialização do setor sucroenergético e o agrohidronegócio no Triângulo Mineiro/Alto Paranaíba. Revista Pegada, vol. 13 n. 1 p. 168-191, 2012.

CLEPS JUNIOR, João; FREITAS, Ricardo Luis; VICTOR, Fabiana Borges. Reforma agrária e ações dos movimentos socioterritoriais do campo em Minas Gerais: 25 anos de lutas e resistências. In.: In: VINHA, Janaina Francisca de Souza Campos (et al). DATALUTA: questão agrária e coletivo de pensamento. São Paulo: Editora Expressão Popular, 2014, p. 191-215.

CLEPS JUNIOR, João (et al.). Relatório DATALUTA MINAS GERAIS - Banco de Dados da Luta pela Terra 2016. Uberlândia: UFU, 2017.

CONAB. Companhia Nacional de Abastecimento. Disponível em: https://www.conab.gov.br/infoagro/safras/cana/boletim-da-safra-de-cana-de-acucar. Acesso em 08 de dez. 2019.

DELGADO, Guilherme Costa. Do Capital Financeiro na Agricultura à Economia do Agronegócio - Mudanças Cíclicas em Meio Século (1965- 2012). Porto Alegre: Editora da UFRGS, 2012, 144 p.

FELICIO, Munir Jorge. Contribuição ao debate paradigmático da Questão Agrária e do Capitalismo Agrário. 2011. 214 f. (Doutorado em Geografia) - Faculdade de Ciências e Tecnologia, Universidade Estadual Paulista, Campus de Presidente Prudente, Presidente Prudente.

FERNANDES, Bernardo Mançano. A ocupação como forma de acesso a terra. Trabalho organizado para apresentação no XXIII Congresso Internacional da LASA. Washington, 2001. Disponível em:

$\begin{array}{lllll}\text { Caminhos de Geografia } & \text { Uberlândia-MG } & \text { v. 22, n. } 79 & \text { Fev/2021 } & \text { p. 262-275 Página } 273\end{array}$


http://www2.fct.unesp.br/nera/publicacoes/fernandes ocupacao.pdf. Acesso em 05 de nov. de 2019.

FERNANDES, Bernardo Mançano. Questão agrária: conflitualidade e desenvolvimento territorial. In: BUAINAIN, A. M. (org.). Luta pela terra, reforma agrária e gestão de conflitos no Brasil. Campinas: Unicamp, 2005.

Os campos da pesquisa em educação do campo: espaço e território como categorias essenciais. A pesquisa em Educação do Campo, v. 20, 2006.

Entrando nos territórios do território. In: PAULINO, Eliane Tomiasi; FABRINI, João Edimilson. Campesinato e territórios em disputa. São Paulo: Expressão Popular, 2008, p. 273-301.

Sobre a tipologia de territórios. In: SAQUET, Marcos Aurélio; SPOSITO Eliseu Savério. Territórios e territorialidades: teorias, processos e conflitos. São Paulo: Expressão Popular, 2009, p. $197-215$.

Construindo um estilo de pensamento na questão agrária: o debate paradigmático e o conhecimento geográfico. 2013. Tese (Livre-Docência em Geografia). Universidade Estadual Paulista, Faculdade de Ciência e Tecnologia. V. 2.

FERNANDES, Bernardo Mançano (et al.). Relatório DATALUTA BRASIL - Banco de Dados da Luta pela Terra 2017. Presidente Prudente: Unesp, 2018.

FERNANDES, Bernardo Mançano; WELCH, Cliff. Campesinato e agronegócio da laranja nos EUA e Brasil. In: FERNANDES, Bernardo Mançano (Org..). Campesinato e agronegócio na América Latina: a questão agrária atual. São Paulo: Clacso e Expressão Popular, 2008, p. 45-70.

FERREIRA, Darlene Aparecida de Oliveira. 0 mundo rural sob o ponto de vista geográfico: a trajetória da geografia agrária brasileira da década de 30 à de 90. 1998. Tese (Doutorado em Geografia) - IGCE, Universidade Estadual Paulista (Unesp), Rio Claro.

FERREIRA, Darlene Aparecida de Oliveira. O Mundo rural e Geografia: geografia agrária no Brasil de 1930-1990. São Paulo: Unesp, 2002.

GIRARDI, Eduardo Paulon. Proposição teórico-metodológica de uma Cartografia Geográfica Crítica e sua aplicação no desenvolvimento do Atlas da Questão Agrária Brasileira. 2008. 347 f. Tese (Doutorado em Geografia). Faculdade de Ciências e Tecnologia (FCT). Universidade Estadual Paulista (Unesp).

GRAMSCl, Antonio. Concepção dialética da história. 8. ed. Rio de Janeiro: Civilização Brasileira, 1978. $341 \mathrm{p}$.

GUIMARÃES, Alberto Passos. Quatro séculos de latifúndio. 6 ed. Rio de Janeiro: Paz e Terra, 1989.

LACOSTE, Yves. A Geografia. Isso serve, em primeiro lugar, para fazer a guerra. 3 ed. Campinas: Papirus, 1988. $133 \mathrm{p}$.

MASSON, Gabriela Abrahão. A Reforma Agrária como política pública de Desenvolvimento: Análise a partir dos Assentamentos Rurais "Tereza do Cedro" e "Dandara" no município de Uberaba/MG. 2016. 407 f. Tese (Doutorado em Serviço Social) - Faculdade de Ciências Humanas e Sociais, Universidade Estadual Paulista "Júlio de Mesquita Filho", Franca, 2016.

MORIN, Edgar. Ciência com consciência. 12 ed. Rio de Janeiro: Bertrand Brasil, 2008.

NOVA CANA. Disponível em: https://www.novacana.com/usinas brasil/estados/minas-gerais?page=3 Acesso em 08 de dez. 2019.

OLIVEIRA, Ariovaldo Umbelino de. A geografia agrária e as transformações territoriais recentes no campo brasileiro. In: CARLOS, Ana F. A. (Org.). Novos caminhos da geografia. São Paulo: Contexto, 1999, p. 63-137.

PEREIRA, Danilo Valentim. Participação política, desenvolvimento territorial e mudança social: um estudo das manifestações dos movimentos socioterritoriais do campo no estado de São Paulo no período 2000-2012. Dissertação (Mestrado em Ciências) - Programa de Pós-Graduação em Mudança Social e Participação Política, Escola de Artes, Ciências e Humanidades, Universidade de São Paulo.São Paulo, 2015,159 f. 
RAMOS FILHO, Eraldo da Silva. Questão agrária atual: Sergipe como referência para um estudo confrontativo das políticas de reforma agrária e reforma agrária de mercado (2003-2006). 2008. 409 f. Tese (Doutorado em Geografia). Faculdade de Ciências e Tecnologia (FCT). Universidade Estadual Paulista (Unesp).

SPOSITO, Eliseu Savério. Geografia e Filosofia. Contribuição para o ensino do pensamento geográfico. São Paulo: Editora Unesp, 2004. 218 p. https://doi.org/10.7476/9788539302741

VICTOR, Fabiana. Conflitos socioespaciais no campo brasileiro: conteúdo das manifestações de luta pela terra em Minas Gerais no início do século XXI. Dissertação (Mestrado em Geografia) Programa de Pós-Graduação em Geografia, Universidade Federal de Uberlândia. Uberlândia, $2016,182 \mathrm{f}$.

VINHA, Janaina Francisca de Souza Campos. Geografia Agrária do Estado de Minas Gerais: análise dos temas e paradigmas (FAPEMIG). Relatório de pesquisa. Uberaba: FAPEMIG, 2019.

Recebido em: 22/03/2020

Aceito para publicação em: 29/09/2020 